Ricardo Franklin de F. Mussi, Leila Maria P. T. Mussi, Atividades Físicas Praticadas no Tempo Livre... Cristiano de S. de Bahia e Angelo Maurício de Amorim

\title{
ATIVIDADES FÍSICAS PRATICADAS NO TEMPO LIVRE EM COMUNIDADE QUILOMBOLA DO ALTO SERTÃO BAIANO
}

Recebido em: $11 / 08 / 2014$
Aceito em: $16 / 03 / 2015$

Ricardo Franklin de Freitas Mussi ${ }^{1}$

Universidade do Estado da Bahia (UNEB)

Jacobina - BA - Brasil

Leila Maria Prates Teixeira Mussi ${ }^{2}$

Universidade Estadual do Sudoeste Baiano (UESB)

Vitória da Conquista - BA - Brasil

Cristiano de Sant'Anna Bahia ${ }^{3}$

Universidade Estadual de Santa Cruz (UESC)

Ilhéus - BA - Brasil

Angelo Maurício de Amorim ${ }^{4}$

Universidade do Estado da Bahia (UNEB)

Jacobina - BA - Brasil

RESUMO: A atividade física constitui importante representação cultural e histórica, sendo influenciada por múltiplas questões e contextualizada em determinado momento, região e população que a pratica. Esse texto identifica as atividades físicas praticadas por adultos de uma comunidade quilombola do alto sertão baiano, em seu tempo livre. A coleta transversal de dados contou com a participação de adultos residentes na comunidade quilombola de Tomé Nunes, situada em Malhada, na Bahia - Brasil. Questionaram-se os entrevistados sobre as atividades físicas realizadas em seu tempo livre. Identificou-se o futebol como a mais praticada por ambos os sexos, independente de faixa etária. No entanto, mais da metade dos adultos quilombolas, principalmente mulheres e pessoas de mais idade, parece não praticar nenhuma atividade física em seu tempo livre.

PALAVRAS CHAVE: Grupos Populacionais. Exercício. Atividades de Lazer. Esportes.

\footnotetext{
${ }^{1}$ Licenciado em Educação Física (UNEB/BA); Mestre em Saúde Coletiva (PPGSC/UEFS/BA). Membro do GEPEECS/CNPq. Doutorando em Educação Física CDS/UFSC/SC. Professor da Universidade do Estado da Bahia UNEB/BA. E-mail: rimussi@yahoo.com.br

${ }^{2}$ Licenciada em História (UNEB/BA); Mestre em História (PPGHIS/UNEB/BA). Líder do GEPEECS/CNPq. Professora da Universidade Estadual do Sudoeste da Bahia - UESB/BA.

3 Licenciado em Educação Física (FEFM/BA); Mestre em Cultura e Turismo (UFBA/BA). Líder do GPPEFEE/CNPq. Doutorando em Educação Física CDS/UFSC/SC. Professor Assistente da Universidade Estadual de Santa Cruz - UESC/BA.

${ }^{4}$ Licenciado em Educação Física (UCSal/BA); Mestre em Educação (UFBA/BA). Membro do GEPEECS/CNPq. Doutorando em Educação Física CDS/UFSC/SC. Professor da Universidade do Estado da Bahia - UNEB/BA.
} 


\section{PHYSICAL ACTIVITIES PERFORMED AT THE PASTIME IN THE QUILOMBOLA COMMUNITY OF HIGH WILDERNESS OF BAHIA STATE}

ABSTRACT: Physical activity is an important cultural and historical representation, it is influenced by multiple questions and contextualized to the moment determined, region and population which practices it. This text identifies the physical activities practiced by adults of the quilombola community of high wilderness in Bahia state, in their free time. The cross data collection counted on adult dwellers of the quilombola community of Thomé Nunes, in Malhada city, Bahia state, Brazil. The interviewed people were questioned about activities carried out in their free time. Soccer was identified as the most practiced activity by both sexes and regardless to the age group. However, more than half of the adults, especially women and elderlies, seem not to practice any physical activity in their free time.

KEYWORDS: Population Groups. Exercise. Leisure Activities. Sports.

\section{INTRODUÇÃO}

A constituição histórica do povo brasileiro, a amplitude territorial e a diversidade cultural do país potencializaram o anonimato social e científico de alguns grupos populacionais, tais como: pobres, campesinos, nortistas, nordestinos, negros. Possivelmente, tal situação resulta do preconceito racial e social e gera negligência, exclusão e escassez informacional.

No século XX, o Brasil foi reconhecido como o país com maior população afrodescendente do mundo (HASENBALG; SILVA, 1999). No início do século XXI, em levantamento do IBGE (2002), mais de 50\% dos brasileiros se autodenominaram negros. O país, no entanto, ainda sofre influência das relações raciais escravagistas, negligenciando o respeito às características e às necessidades da maioria de sua população.

A redemocratização brasileira, em 1988, após mais de duas décadas de violação de direitos humanos pelo regime militar, despertou a sociedade para luta pela dignidade pública e pessoal. Valor inexistente, por quase cinco séculos, para muitos cidadãos menos privilegiados, especialmente para os negros. 
Ricardo Franklin de F. Mussi, Leila Maria P. T. Mussi, Atividades Físicas Praticadas no Tempo Livre... Cristiano de S. de Bahia e Angelo Maurício de Amorim

Os movimentos iniciados na década de 1970, em defesa dos direitos dos negros, pretendendo justiça social para os quilombolas, conquistaram direitos civis, políticos e administrativos (MARQUES; GOMES, 2013). O artigo 215 da Constituição Federal brasileira afirma que a garantia dos direitos culturais e a proteção das comunidades afrobrasileiras é função do Estado (BRASIL, 1988).

Os quilombos contemporâneos diferem dos quilombos históricos. Estes eram habitados por escravos fugidos. Os atuais são formados por descendentes de escravos, que mantêm laços de parentesco e praticam cultura de subsistência. Seus ascendentes nem sempre foram negros fugidos.

Passados mais de 25 anos de seu reconhecimento legal, os quilombos contemporâneos ainda sofrem com a negligência política, social e científica. Estudos sobre essas comunidades são bastante recentes, havendo poucos interlocutores dedicados a suas problemáticas, especialmente no que tange às práticas culturais no campo da atividade física.

As atividades físicas ultrapassam as questões biológicas, pois sofrem influência de fatores socioculturais (NAHAS, 2013), como das relações sociais, da infraestrutura e da mídia (MARQUES; GAYA, 1999). Dentre as atividades físicas, incluem-se aquelas desvinculadas de obrigações e praticadas durante o tempo livre. Geralmente, elas envolvem ginástica, exercícios, dança, luta, esportes e as manifestações culturais.

O tempo livre deve proporcionar ao sujeito o máximo autocondicionamento e o mínimo de heterocondicionamento. Ele deve ser usufruído com liberdade e criatividade, como verdadeiro ócio, evitando-se a influência de ideias consumistas, mercantilistas e coisificantes (AQUINO; MARTINS, 2007). Esse momento deve ser ocupado por 
Ricardo Franklin de F. Mussi, Leila Maria P. T. Mussi, Atividades Físicas Praticadas no Tempo Livre... Cristiano de S. de Bahia e Angelo Maurício de Amorim

atividades que tragam satisfação e desenvolvimento pessoal e coletivo, livres de pressões socioeconômicas.

A atividade física de tempo livre (AFTL) tem merecido atenção de disciplinas pertinentes ao campo da saúde, uma vez que pessoas pouco ativas nessa dimensão costumam apresentar rendimento insuficiente nas atividades físicas cotidianas (CASPERSEN; MERRIT; STEPHENS, 1995). Pessoas sedentárias ou pouco ativas no tempo livre apresentam maior probabilidade de redução da aptidão física geral e das condições de saúde.

Níveis ideais de AFTL costumeiramente se correlacionam com melhores indicadores de bem-estar psicológico (WARBURTON; NICOL; BREDIN, 2006) e de relações sociais positivas (WEINBERG; GOULD, 2008). O desenvolvimento de AFTL contribui para a promoção multidimensional da saúde, uma vez que são reconhecidos seus benefícios tanto biológicos quanto psicológicos e sociais.

O interesse pela temática da AFTL relacionada às comunidades quilombolas é recente, havendo restrito número de estudos sobre o assunto (DIAS, 2011).

A falta de informação sobre as práticas de AFTL desenvolvidas por sujeitos quilombolas dificulta, ou mesmo inviabiliza, a organização e a implantação de políticas públicas que respeitem suas necessidades e especificidades, particularmente as relativas ao esporte em suas múltiplas dimensões. Tal desconhecimento amplia o risco de desrespeito às características culturais, sociais, políticas e ambientais destas comunidades, quando da elaboração e da implementação de políticas públicas para atendê-las.

Esse artigo identifica as atividades físicas praticadas por adultos de uma comunidade quilombola do alto sertão baiano em seu tempo livre. 
Ricardo Franklin de F. Mussi, Leila Maria P. T. Mussi, Atividades Físicas Praticadas no Tempo Livre... Cristiano de S. de Bahia e Angelo Maurício de Amorim

\section{PROCEDIMENTOS METODOLÓGICOS}

O presente estudo, de caráter transversal, descritivo e exploratório, é parte da pesquisa "Comunidades Negras Quilombolas Baianas: antropometria aumentada e atividades físicas reduzidas como fatores de risco à saúde" (CEP/UEFS nº 158/2011).

A comunidade de Tomé Nunes, alvo desta investigação, situa-se a $12 \mathrm{~km}$ do perímetro urbano de Malhada - município baiano do nordeste brasileiro, com cerca de 16.058 habitantes e desenvolvimento humano médio, segundo dados do IBGE (2014). Localiza-se em área rural, à margem direita do Rio São Francisco, contando com acesso por estrada vicinal, não asfáltica. É constituída por famílias que vivem da agricultura de subsistência e do pequeno comércio em feiras da região. Ela foi reconhecida pela Fundação Cultural Palmares como remanescente quilombola, após trâmite legal concluído em dezembro de 2004 (TEIXEIRA, 2011).

No presente artigo, quando necessário, usa-se o termo 'comunidade' como referência à localidade estudada, visto que os moradores assim se autorreconhecem (TEIXEIRA, 2010).

A comunidade possui uma escola de Ensino Fundamental, de pequeno porte. $\mathrm{O}$ serviço de saúde dispõe de uma agente comunitária (que atende mais de uma comunidade rural), de serviço odontológico uma vez por semana e de atenção médica irregular.

Após contato prévio com a Associação de Moradores de Tomé Nunes, foram agendadas e realizadas visitas à comunidade, no período de outubro e novembro de 2012, visando conhecer o objeto de estudo e coletar dados necessários para a pesquisa. 
Ricardo Franklin de F. Mussi, Leila Maria P. T. Mussi, Atividades Físicas Praticadas no Tempo Livre... Cristiano de S. de Bahia e Angelo Maurício de Amorim

As informações analisadas foram coletadas por intermédio da aplicação de questionário estruturado a 112 sujeitos, adultos ( $\geq 18$ anos), de ambos os sexos, residentes na comunidade. Eles foram selecionados aleatoriamente e, depois de esclarecidos sobre as principais questões da pesquisa, aceitaram dela participar, tendo assinado o Termo de Consentimento Livre e Esclarecido.

O questionário abrangeu tanto informes demográficos (idade - em anos completos - e sexo - masculino e feminino) quanto questões sobre a regularidade e a modalidade de AFTL, através das perguntas: "Nos últimos três meses, o(a) senhor(a) praticou algum tipo de exercício físico ou esporte?”; “O(a) senhor(a) pratica o exercício pelo menos uma vez por semana?”; “Qual o tipo principal de exercício físico ou esporte que o(a) senhor(a) praticou?" (estas três perguntas integram o inquérito do VIGITEL 2011) - (BRASIL, 2012).

As respostas às duas primeiras perguntas permitiram identificar a regularidade da prática. As respostas à terceira indagação foram aceitas como AFTL corriqueiramente praticada pelos quilombolas.

Durante a aplicação do questionário, foi reforçado que AFTL são atividades realizadas com fins meramente recreacionais ou de lazer, ou seja, praticadas fora do horário do trabalho, não relacionadas ao cuidado pessoal (higiene, alimentação) ou domiciliar (faxina, preparo alimentar), ou feitas em deslocamentos (por exemplo, caminhar ou pedalar para ir ao trabalho ou à escola ou deles voltar ).

Para a efetivação da análise, as atividades com características esportivas foram agrupadas. Por exemplo, natação inclui 'nadar no rio' e outras atividades aquáticas (FERREIRA; KLEINUBING, 2003); ciclismo representa o conjunto de atividades 
Ricardo Franklin de F. Mussi, Leila Maria P. T. Mussi, Atividades Físicas Praticadas no Tempo Livre... Cristiano de S. de Bahia e Angelo Maurício de Amorim

relativas a 'andar de bicicleta' (CARVALHO; FREITAS, 2012), embora se reconheça que elas não apresentam todas as características do esporte formal.

Através dessas informações, caracterizaram-se os participantes e estratificou-se a análise das AFTL, conforme o sexo biológico (masculino e feminino) e o grupo etário (mais novos e mais velhos, segmentados pela mediana da idade, 39 anos).

\section{RESULTADOS}

A média de idade dos participantes dessa investigação na comunidade quilombola de Tomé Nunes foi de 42,13+18,52 anos. No grupo pesquisado, 55,4\% eram mulheres; $36,6 \%$ declararam a prática de exercícios ou de algum esporte nos últimos 3 meses; $35,7 \%$ afirmaram que tal prática ocorreu ao menos uma vez por semana.

Quadro 1 - Atividades físicas de tempo livre (AFTL) em adultos quilombolas, Tomé Nunes, Malhada, Bahia, Brasil, 2012. (n=112)

\begin{tabular}{|l|l|}
\hline AFTL desenvolvida & Percentual / Quantidade \\
\hline Caminhada & $\mathbf{9 , 8 \% ( 1 1 )}$ \\
\hline Corrida & $1,8 \%(2)$ \\
\hline Natação (atividades aquáticas) & $4,5 \%(5)$ \\
\hline Ciclismo (andar de bicicleta) & $4,5 \%(5)$ \\
\hline Futebol & $\mathbf{2 0 , 5 \% ( 2 3 )}$ \\
\hline Outras atividades & $6,3 \%(7)$ \\
\hline Nenhuma Atividade declarada & $\mathbf{5 2 , 7 \% ( 5 9 )}$ \\
\hline
\end{tabular}

Fonte: Dados da pesquisa, 2012.

Dentre os participantes, 47,3\% declararam prática de alguma AFTL. O futebol (20,5\%) evidenciou-se como a atividade predominante e a caminhada $(9,8 \%)$, como a segunda atividade mais praticada. Embora de maneira restrita, atividades físicas como 
Ricardo Franklin de F. Mussi, Leila Maria P. T. Mussi, Atividades Físicas Praticadas no Tempo Livre... Cristiano de S. de Bahia e Angelo Maurício de Amorim

corrida, natação (atividades aquáticas) e ciclismo (andar de bicicleta) também foram referidas. (QUADRO 1).

Dentre os praticantes de atividade em seu tempo livre, predominaram os homens, totalizando $58,49 \%$ dos declarantes. O futebol $(28,3 \%)$ é a modalidade mais desenvolvida por eles, seguida pela natação $(9,43 \%)$. Entre as mulheres ocorreu igualdade entre a prática de futebol e a caminhada $(15,09 \%)$ como primeira atividade mais executada. (TABELA 1).

Tabela 1 - Relação entre sexo biológico e atividades físicas de tempo livre em adultos quilombolas, Tomé Nunes, Malhada/BA, 2012. ( $\mathrm{n}=112)$.

\begin{tabular}{|c|c|c|c|c|}
\hline & & SEXO & & TOTAL \\
\hline & & Feminino & Masculino & \\
\hline \multirow[t]{7}{*}{ AFTL } & Caminhada & $15,09 \%(8)$ & $5,66 \%(3)$ & $20,75 \%(11)$ \\
\hline & Corrida & $0,00 \%(0)$ & $3,77 \%(2)$ & $3,77 \%(2)$ \\
\hline & Natação & $0,00 \%(0)$ & $9,43 \%(5)$ & $9,43 \%(5)$ \\
\hline & Ciclismo & $3,77 \%(2)$ & $5,66 \%(3)$ & $9,43 \%(5)$ \\
\hline & Futebol & $15,09 \%(8)$ & $28,30 \%(15)$ & $43,4 \%(23)$ \\
\hline & Outros(as) & $7,55 \%(4)$ & $5,66 \%(3)$ & $13,21 \%(7)$ \\
\hline & Total de praticantes & $41,51 \%(22)$ & $58,49 \%(31)$ & $100 \%(53)$ \\
\hline & Atividade não declarada & $67,80 \%(22)$ & $58,49 \%(31)$ & $100 \%(53)$ \\
\hline
\end{tabular}

Fonte: dados da pesquisa, 2012.

Com relação aos grupos etários, entre os mais jovens ocorreu o predomínio do futebol $(33,96 \%)$, sendo a caminhada $(9,43 \%)$ a segunda atividade mais citada. Entre os mais velhos, o futebol e a caminhada se igualaram $(9,43 \%)$ como a atividade mais desenvolvida. (GRÁFICO 1).

Aqueles que disseram não praticarem nenhuma AFTL totalizaram 52,7\% dos participantes (QUADRO 1), sendo 67,8\% mulheres (Tabela 01) e 66,1\% pertencentes ao grupo dos mais velhos (GRÁFICO 1). 
Ricardo Franklin de F. Mussi, Leila Maria P. T. Mussi, Atividades Físicas Praticadas no Tempo Livre... Cristiano de S. de Bahia e Angelo Maurício de Amorim

Gráfico 01 - Relação entre grupo etário e atividades físicas de tempo livre em adultos quilombolas, Tomé Nunes, Malhada/BA, 2012. $(\mathrm{n}=112)$.



Fonte: Dados da pesquisa, 2012.

\section{DISCUSSÃO}

Em Tomé Nunes, foram identificadas especificidades nas práticas das AFTL entre os adultos. As modalidades variaram segundo o sexo e/ou grupo etário. As ações culturais quilombolas surgem em contextos diferenciados, conforme a localização geográfica, o momento histórico e as relações estabelecidas com agentes e culturas externas. No caso de Tomé Nunes, foram identificadas práticas de caminhada, corrida, 
Ricardo Franklin de F. Mussi, Leila Maria P. T. Mussi, Atividades Físicas Praticadas no Tempo Livre... Cristiano de S. de Bahia e Angelo Maurício de Amorim

ciclismo (andar de bicicleta), natação (atividades aquáticas) e futebol como as alternativas mais comuns para a ocupação recreativa do tempo livre dos adultos.

A caminhada resulta de um movimento natural e fácil, não exigindo equipamento específico. Devido à melhoria do condicionamento físico, ela proporciona bons resultados na promoção da saúde e na qualidade de vida (MAZO; LOPES; BENEDETTI, 2009). Reconhecida como uma atividade muito praticada e facilmente acessível, ela possui praticantes em diversas faixas etárias e grupos étnicos (BASSET Jr. et al., 2008).

Essas características ajudam a entender por que, na comunidade investigada, a caminhada é a segunda modalidade mais executada, no cômputo geral, sendo a primeira entre as mulheres e entre os mais velhos (com quantitativo similar ao futebol) e a segunda entre os mais novos. Ressalta-se que a caminhada mencionada pelos moradores de Tomé Nunes não está relacionada aos deslocamentos, tendo sido considerados apenas os momentos de passeio (descontração) ou de prática de exercício físico (promoção da saúde).

A prática esportiva identificada como primeira opção geral de atividade para ocupação do tempo livre em Tomé Nunes, não segue a estrutura formal, está contextualizada às características, necessidades e especificidades locais. O quilombo é uma comunidade rural, negra, desprovida de infraestrutura esportiva, mas não de cultura nem de capacidade para adequar o esporte formal a fim de atender sua realidade e suas necessidades de recreação e ocupação do tempo livre.

Neste sentido, aponta-se que a análise do fenômeno esportivo permite a identificação e a compreensão de mudanças e transformações sociais (MOURA et al., 2010). É carregado de normas, valores e representações, segundo a estrutura social, o 
Ricardo Franklin de F. Mussi, Leila Maria P. T. Mussi, Atividades Físicas Praticadas no Tempo Livre... Cristiano de S. de Bahia e Angelo Maurício de Amorim

estilo de vida e a comunidade praticante (STIGGER, 2005), tornando-se importante no processo de aquisição da cidadania (DIAS; FONSECA, 2011).

O futebol foi a AFTL mais referenciada pelos entrevistados, quer por sexo, quer por grupo etário. Outras atividades foram citadas pela comunidade e são discutidas na sequência.

Estudo memorialístico destaca o futebol como uma das representações culturais de Tomé Nunes, juntamente com a casa de orações, a folia de reis e outras festas e dança (TEIXEIRA, 2013b). A atividade futebolística diz respeito à recreação e à ocupação do tempo livre dos adultos, mas também à organização e à mobilização política, por contribuir para a estruturação e o desenvolvimento cultural e social quilombola.

É importante citar que o 'futebol quilombola' é, provavelmente, bastante diferente daquele competitivo, formal, apresentado nas mídias de massa. Suas regras (quantidade de jogadores e tempo de partida) e equipamentos (dimensões da área de jogo e uniformes) são adaptados para atrair e manter o envolvimento dos residentes com a atividade futebolística.

A irredutibilidade ou especificidade de uma manifestação implica o estabelecimento de condições de admissão de um fenômeno como elemento de cultura (SODRÉ, 2005). Esta consideração sugere que o esporte deve ser incentivado e preservado em Tomé Nunes, por estar impregnado de multiplicidade simbólica e identitária.

Um importante motivador para a ampla prática de futebol na comunidade é a presença de equipamentos públicos específicos para seu desenvolvimento. O quilombo conta com um campo de futebol, em dimensões próximas às oficiais, localizado na 
Ricardo Franklin de F. Mussi, Leila Maria P. T. Mussi, Atividades Físicas Praticadas no Tempo Livre... Cristiano de S. de Bahia e Angelo Maurício de Amorim

principal via de acesso e de trânsito (IMAGEM 1). Há ainda outros campos menores, distribuídos nas proximidades das residências (IMAGEM 2).

Imagem 1: Principal campo de futebol localizado na entrada da comunidade de Tomé Nunes/BA. Fonte: Foto de Leila Maria Prates Teixeira, 26 de outubro de 2012.

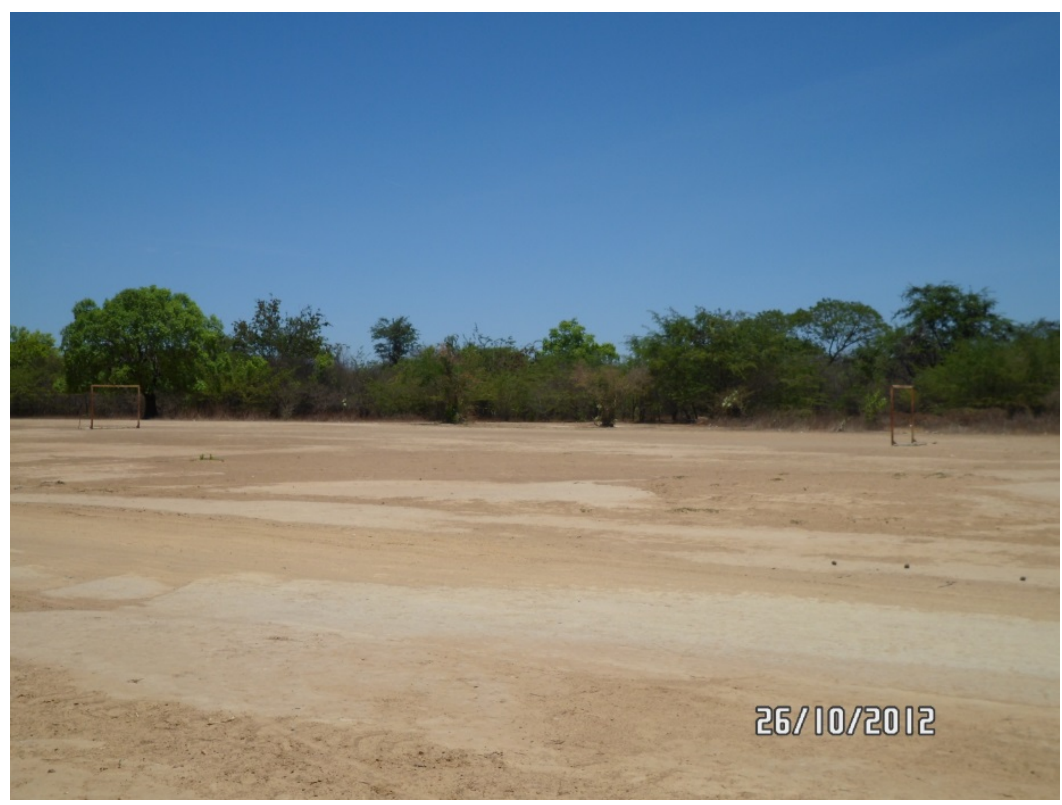

Imagem 2: Um dos pequenos campos de futebol da comunidade de Tomé Nunes/BA.



Fonte: Foto de Leila Maria Prates Teixeira, 26 de outubro de 2012 
Ricardo Franklin de F. Mussi, Leila Maria P. T. Mussi, Atividades Físicas Praticadas no Tempo Livre... Cristiano de S. de Bahia e Angelo Maurício de Amorim

Similaridades ao presente estudo foram verificadas em quilombos amazonenses (FREITAS, SILVA, GALVÃO, 2009), paranaenses (LARA, 2012) e goianos (DIAS, 2011). Foram, porém, encontrados múltiplos 'futebóis', cada um atendendo especificidades ambientais e socioculturais de seu agrupamento comunitário.

Por exemplo, em Tomé Nunes, existem vários locais para jogos de futebol, sendo fortes as práticas recreativa e competitiva (campeonatos internos são comuns, participações externas, por convite, ocorrem esporadicamente). $\mathrm{Na}$ comunidade de Saracura, a atividade futebolística é interrompida no período das chuvas, quando os diversos campos de jogo ficam inundados (FREITAS, SILVA, GALVÃO, 2009). Esta situação interfere negativamente em seu desenvolvimento recreativo e, praticamente, inviabiliza seu desenvolvimento competitivo, que demanda prática contínua.

Em Córrego do Franco, há um campo de futebol, compartilhado para a prática recreativa e a para o treinamento de um time, havendo concorrência em dias e horários entre o jogo descompromissado e o treino ou jogo competitivo. No campo de Invernada Paiol da Telha, a prática recreacional fica restrita aos finais de semana (LARA, 2012). Em Cedro, Goiás, a prática competitiva é forte, contando com uma equipe conhecida na região. Em Almeida, no mesmo estado, esse desporto restringe-se à ocupação do tempo livre (DIAS, 2011).

Esse quadro futebolístico diversificado, existente nas comunidades de negros quilombolas, em diferentes regiões e estados brasileiros, corrobora a ideia de que o futebol é o 'esporte nacional'. O intenso apelo midiático estimula sua prática. Ela é, frequentemente, 'facilitada' ou adaptada às características dos espaços. Por vezes, basta a presença de uma bola (mesmo que feita de meias) para que o jogo aconteça. O futebol tornou-se uma atividade física praticamente hegemônica e comum a todo o território 
Ricardo Franklin de F. Mussi, Leila Maria P. T. Mussi, Atividades Físicas Praticadas no Tempo Livre... Cristiano de S. de Bahia e Angelo Maurício de Amorim

brasileiro, pois está presente até mesmo em comunidades distantes e que possuem especificidades culturais, como as quilombolas. A presença do futebol nos mais variados agrupamentos constitui um mecanismo de consolidação identitária e cultural, de mobilização social e política.

A recorrência da prática futebolística nos mais diversificados grupos indica sua apropriação pela cultura brasileira (ALMEIDA; ALMEIDA; GRANDO, 2010). Esse esporte assume importante papel na representação da brasilidade. Ele aproxima os indivíduos, desde os moradores das grandes cidades até os quilombolas do interior do Brasil, pela exacerbação do sentimento de brasilidade e por sua característica de cultura de massa.

O futebol é um dos formadores da cultura popular, heterogênea, constituída por elementos antagônicos. Ele se incorporou à cultura do imigrante, às heranças africanas, ao contexto das classes subalternas e dos membros da elite. (MALAIA, 2008).

Em Tomé Nunes, assim como em outros quilombos, e possivelmente nos demais agrupamentos populacionais brasileiros, a vivência esportiva informal produz características especiais e adequações às especificidades ambientais, sociais e econômicas. Estas alterações viabilizam a melhor participação tanto dos jogadores como dos espectadores.

O futebol chegou ao Brasil, no século XIX, para atender os anseios elitistas, para preencher o ócio aristocrático (fruição do tempo livre) de espectadores e de praticantes (HOLLANDA, 2011). No entanto, sua popularização ocorreu rapidamente, inclusive entre negros, mulatos e pobres (DAÓLIO, 2000), contrariando sua gênese para ser o 'engrandecimento da raça' elitizada (MALAIA, 2008). 
Ricardo Franklin de F. Mussi, Leila Maria P. T. Mussi, Atividades Físicas Praticadas no Tempo Livre... Cristiano de S. de Bahia e Angelo Maurício de Amorim

Diferenciações em relação à expressão esportiva formal e certo grau de afastamento da ação esportiva aristocrática não significam ausência de normatizações nas atividades esportivas dos quilombolas (DIAS, 2010). O que ocorre são ajustamentos das normas a serem cumpridas, para que estas correspondam às demandas e às exigências locais e possibilitem a autogestão do jogo desportivo, participativo ou competitivo.

A atividade futebolística brasileira obteve reconhecimento internacional, invertendo a lógica da tradicional dependência de potências europeias (HOLLANDA, 2011). O protagonismo brasileiro praticamente força os clubes dos países que sediam os mais importantes campeonatos do mundo a virem em busca de atletas 'diferenciados' para compor seus elencos.

A inserção de negros no futebol brasileiro contribuiu para que os trabalhadores com ele se identificassem. A atividade originalmente oligárquica se popularizou, vindo a ser praticada por negros, mestiços e brancos pobres, dentre os quais emergiram os melhores jogadores (MALAIA, 2008). O bom desempenho atlético dos desportistas negros reforça a identidade esportiva desta população e a constituição étnica diferenciada da nação (HOLLANDA, 2011).

Outra importante questão relativa à presença negra nesse esporte é a criação de 'zonas livres' de circulação, espaços de mistura e hibridismo, permissivo de linguagens e práticas desafiadoras do poder puritano oficial (ARCHETTI, 2003). Nestas zonas ocorrem a integração e a visibilidade social do negro, sendo o futebol assumido como 'espaço implicitamente negro' ou 'área leve' de racismo (ABRAHÃO; SOARES, 2012). 
Ricardo Franklin de F. Mussi, Leila Maria P. T. Mussi, Atividades Físicas Praticadas no Tempo Livre... Cristiano de S. de Bahia e Angelo Maurício de Amorim

A inclusão e o sucesso negro no campo futebolístico são exemplos, embora simplificados, de promoção da igualdade racial e social, simbolizando local e/ou momento de ruptura com o excludente modelo racial e econômico brasileiro, existente desde o período colonial. A ação esportiva quilombola é não só uma estratégia para ocupar o tempo livre, através de seu papel recreativo interno à comunidade, mas também é ação política para a inserção dos quilombolas na vida social do município, os quais passarão a ser reconhecidos pelas demais comunidades tanto quilombolas como rurais e urbanas.

A prática esportiva no tempo livre, recreativa ou competitiva, permite o reconhecimento de especificidades, diferenciações e adequações dos grupos populacionais correspondentes a suas necessidades, seus desejos e sua realidade. No Brasil, a prática esportiva pode evidenciar momentos em que a cor da pele não representa barreira ou critério para exclusão (ABRAHÃO; SOARES, 2012), oportunizando a promoção da igualdade racial.

Quanto a outras atividades físico-esportivas, a comunidade ribeirinha de Tomé Nunes/BA não possui estruturas formais (ginásios, quadra, piscina, entre outros) para a prática de determinados esportes. Como está localizada em uma região cujo clima caracteriza-se pelas altas temperaturas, a prática da natação (nadar no rio) é algo presente. Nos dias mais quentes as pessoas se refrescam no rio, quando também organizam jogos e brincadeiras. A prática de nadar é viabilizada exclusivamente pela presença do Rio São Francisco, não atendendo as especificações nem as modalidades do nado formal.

As características estruturais e educacionais desta comunidade quilombola permitem afirmar que a natação aí desenvolvida afasta-se da representação da 
Ricardo Franklin de F. Mussi, Leila Maria P. T. Mussi, Atividades Físicas Praticadas no Tempo Livre... Cristiano de S. de Bahia e Angelo Maurício de Amorim

modalidade formal. A prática da 'natação quilombola' se aproxima da ideia da interrelação entre água, corpo e prazer (FERREIRA; KLEINUBING, 2003). Certamente o enfoque da 'natação quilombola' não é atingir a performance das modalidades atléticas.

Quanto à opção por atividades no ambiente aquático, assim como em Tomé Nunes, em outras comunidades ribeirinhas também há a prática de natação (FREITAS, SILVA, GALVÃO, 2009; LARA, 2012; DIAS, 2011), ou seja, de atividades feitas dentro d'água. Percebe-se a ausência de políticas públicas que viabilizem a implantação de equipamentos e a oportunidade de ensinamentos esportivos nestas comunidades.

A Política Nacional de Esporte, promulgada no ano de 2003, inclui, em seu texto, as extensões informais (recreacionais e participativas). Desde então, houve crescimento do orçamento destinado à implantação e ao desenvolvimento esportivo em suas múltiplas dimensões. No entanto, verifica-se o distanciamento entre o legislado e o concreto e, por isto, se questiona: quanto desta verba é direcionado às regiões pobres, eminentemente negras e periféricas? E às comunidades quilombolas? E para o esporte com enfoque participativo comunitário e recreacional?

No que tange às diferenciações das AFTL segundo o sexo biológico, em Tomé Nunes, os homens constituem maioria absoluta dos que as desenvolvem (58,49\%). Inversamente, entre aqueles que declararam não praticar nenhuma atividade física em seu tempo livre, há predomínio das mulheres $(67,8 \%)$. Essas diferenças indicam que a fruição do ócio é um ganho eminentemente masculino, mesmo em uma comunidade quilombola.

Com referência à modalidade praticada, também há diferenças entre os sexos. No grupo masculino, há preferência pelo futebol e, no grupo feminino, ocorre igualdade entre caminhada e futebol. Tais informações evidenciam que as mulheres da 
Ricardo Franklin de F. Mussi, Leila Maria P. T. Mussi, Atividades Físicas Praticadas no Tempo Livre... Cristiano de S. de Bahia e Angelo Maurício de Amorim

comunidade, escolhem exercícios de menor intensidade e exigência física. A existência de mulheres futebolistas em Tomé Nunes representa uma conquista advinda da luta por sua presença em um ambiente predominantemente masculino.

Discursos pejorativos e contrários à mulher esportista resultam de uma construção histórica. Em meados do século XIX, a sociedade brasileira não permitia a participação feminina em ambientes esportivos, por considerar que eles representavam uma ameaça às mulheres, por chamar a atenção para elas em um universo alicerçado em valores masculinos e por eles dominado, o que colocaria em risco a feminilidade (GOELLNER, 2005).

Essa situação reforçou a desigualdade social entre os sexos, pois as mulheres apresentam menor disponibilidade de tempo livre; têm menos oportunidades para participarem de atividades recreativas; vivenciam prioritariamente o lazer doméstico; são responsáveis pelas atividades ligadas à manutenção do lar e à criação dos filhos (BARBOSA; LIECHTY; PEDERCINI, 2013). Esta situação corrobora a ideia de que as práticas humanas produzem e reproduzem representações de feminilidade e de masculinidade (GOELLNER et al, 2009).

Assim como no quilombo baiano investigado, nas comunidades goianas (DIAS, 2011) e em Murumutuba, Amazonas (FREITAS, SILVA, GALVÃO, 2009) é relatado que ambos os sexos jogam futebol. No entanto, em quilombos paranaenses, esta modalidade aparece como exclusivamente masculina (LARA, 2012), reforçando a diferenciação entre os sexos. Em Saracura, Amazonas, é observado o preconceito quanto à participação feminina do futebol (FREITAS, SILVA, GALVÃO, 2009).

Em Tomé Nunes e nas primeiras comunidades anteriormente citadas, nota-se a luta pela superação da segmentação social por sexo. No entanto, nas últimas 
Ricardo Franklin de F. Mussi, Leila Maria P. T. Mussi, Atividades Físicas Praticadas no Tempo Livre... Cristiano de S. de Bahia e Angelo Maurício de Amorim

comunidades referidas é reforçada a compreensão de que, no Brasil, o futebol é prática eminentemente masculina (MOURA et al, 2010). Tal atitude gera o preconceito machista contra as mulheres, sob a alegação de que o futebol masculiniza a jogadora e de que são inerentes às mulheres a fragilidade e a ausência de habilidades para este esporte.

O importante predomínio do futebol como principal AFTL feminina em Tomé Nunes, diferentemente do que foi encontrado em populações similares em outros estados brasileiros, pode ser explicado pelo restrito acesso da comunidade a outras modalidades esportivas ou atividades físicas devido à ausência de uma política intervencionista ou educacional específica. Por exemplo, a comunidade do Feixo, Paraná, conta com ação do Programa Segundo Tempo, que influencia a variabilidade das atividades desenvolvidas por esses quilombolas (LARA, 2012).

Em Tomé Nunes, as mulheres assumem relevância seja em atividades comuns do dia a dia, seja em momentos de movimentação política ou em festividades (TEIXEIRA, 2013). É recorrente a presença feminina na liderança da Associação de Moradores. Muitas mulheres também são provedoras do lar. Por consequência, como o futebol é uma prática corriqueira na comunidade, elas não aceitam serem excluídas desta atividade comunitária, a qual desempenha importante papel político.

As práticas corporais, em comunidades tradicionais, expressam valores, costumes, normas sociais e comportamentos desejados a serem incorporados por seus integrantes (ALMEIDA; ALMEIDA; GRANDO, 2010). Nos torneios e campeonatos organizados pela comunidade de Tomé Nunes ou em outras localidades, com sua participação, não é incomum a presença das mulheres nas partidas de futebol. Isto 
Ricardo Franklin de F. Mussi, Leila Maria P. T. Mussi, Atividades Físicas Praticadas no Tempo Livre... Cristiano de S. de Bahia e Angelo Maurício de Amorim

representa um importante movimento visando à interação entre os sexos e à superação do sexismo esportivo, tornando-se um exemplo para grupos comunitários distintos.

A continuidade e reforço da diferenciação entre os sexos reverberam negativamente nas oportunidades, no acesso e na execução das mais variadas atividades intra e extracomunitárias. No entanto, poucas vezes o quesito sexo é considerado como fator relevante no processo de elaboração das políticas públicas brasileiras no que tange ao esporte (GOELLNER et al, 2010) em suas múltiplas representações sociais.

A igualdade entre os sexos ainda está em processo de concretização em Tomé Nunes e nos demais agrupamentos sociais brasileiros. A diferenciação entre os sexos encontrada no presente estudo corrobora indicativos quanto ao padrão de atividade física desfavorável às mulheres. Entre elas há mais pessoas insuficientemente ativas, nas diversas faixas etárias, devido, principalmente, a fatores socioculturais (PETROSKI; OLIVERIA, 2008).

Com o crescimento da expectativa de vida, o envelhecimento vem assumindo importância nas áreas científica e profissional, que buscam a compreensão das questões desta faixa etária. Pesquisas focadas nas atividades físicas recreacionais abrirão possibilidades para a implementação de ações voltadas para a manutenção ou a retomada da autonomia, da independência, da saúde e da qualidade de vida dos idosos.

As análises sobre o envelhecimento, com viés biologicista, começaram a ser desenvolvidas nos séculos XIX e XX, devido aos avanços da medicina (SILVA, 2008). As questões sociológicas, no entanto, emergiram somente a partir da década de 1960 (SIQUEIRA, 2002).

O envelhecimento representa uma etapa do percurso da vida. A própria condição de estar vivo é processo, transformação e movimento. Os acontecimentos 'se' e 'nos' 
Ricardo Franklin de F. Mussi, Leila Maria P. T. Mussi, Atividades Físicas Praticadas no Tempo Livre... Cristiano de S. de Bahia e Angelo Maurício de Amorim

transformam, com o entrelace da vivência de crianças, jovens e velhos (DEBORTOLI, 2012).

As especificidades e os desejos envolvidos diferem segundo os vários grupos comunitários, cada qual vendo o envelhecimento de maneira peculiar. As intervenções profissionais em prol da manutenção ou do aperfeiçoamento da qualidade de vida devem, pois, respeitar a cultura local.

O envelhecer não pode ser atrelado exclusivamente às perdas advindas da passagem dos anos nem ao fato desses decréscimos se refletirem na vida privada. $\mathrm{O}$ envelhecimento é uma importante questão social (ACOSTA; PACHECO, 2013).

Em Tomé Nunes, dentre os que declaram exercerem práticas atléticas em seu tempo livre, os adultos mais novos as executam com maior regularidade do que os mais velhos. O futebol figura como principal experiência vivenciada pelos dois grupos. A caminhada é segunda atividade mais praticada por ambos os grupos etários.

Não é incomum, entre quilombolas de outras regiões e estados brasileiros, a preferência pelo futebol. Provavelmente isto resulta de uma construção histórica que o favoreceu e gerou a associação identitária nacional com a modalidade.

A presença da caminhada é recorrente devido à naturalidade motora dos movimentos e à pouca exigência de equipamentos para sua execução.

Além do futebol e da caminhada, os moradores adultos de Tomé Nunes referiram a prática regular de ciclismo (andar de bicicleta), natação (atividades aquáticas) e corrida. Embora sua tímida presença, especialmente diante dos índices relativos ao futebol, estas referências evidenciam certa diversificação nas atividades recreativas da comunidade quilombola. 
Ricardo Franklin de F. Mussi, Leila Maria P. T. Mussi, Atividades Físicas Praticadas no Tempo Livre... Cristiano de S. de Bahia e Angelo Maurício de Amorim

As escolhas das práticas corporais por grupos específicos demonstram seu pensamento coletivo, constituem um espaço-tempo pedagógico e significam a afirmação de seu habitus (ALMEIDA; ALMEIDA; GRANDO, 2010). As opções presentes em Tomé Nunes resultam do contexto histórico, cultural, educacional e geográfico ali vivenciado.

O ciclismo (andar de bicicleta) é um importante, barato e democrático meio de transporte, sendo ecológico e saudável (CARVALHO; FREITAS, 2012). Não é incomum sua prática como atividade recreativa e prazerosa durante o tempo livre, tal qual citado pelos quilombolas.

O termo ciclismo denomina toda atividade física feita com utilização de bicicleta e, pode corresponder, entre outras funções, à ocupação do tempo livre, quando se caracteriza pela ausência do elemento competitivo e pela conotação recreativa (ROLDAN, 2000). O ciclismo no quilombo relaciona-se ao ato de pedalar durante um passeio solitário ou em grupo, desde que não esteja ligado a deslocamentos para trabalhar ou estudar, não havendo necessidade de uma pista especial para esse fim.

Provavelmente a insuficiente infraestrutura e a falta equipamentos no quilombo - vias em precário estado de conservação e bicicletas inadequadas (pesadas e com tamanhos inadequados aos usuários) - dificultam a adesão dos quilombolas ao ciclismo em seu tempo livre. Contudo, essa é uma atividade importante quando se trata dos deslocamentos de um ponto a outro.

Fato interessante é que a coleta de dados, feita junto a moradores desta comunidade, situada à margem direita do Rio São Francisco, os quais têm na pesca uma de suas atividades de subsistência, não apresentou, de maneira recorrente, adesão às 
Ricardo Franklin de F. Mussi, Leila Maria P. T. Mussi, Atividades Físicas Praticadas no Tempo Livre... Cristiano de S. de Bahia e Angelo Maurício de Amorim

atividades aquáticas. Isto demonstra a pouca compreensão de que o espaço de trabalho também pode também ser utilizado para distração e lazer.

Assim como em relação ao ciclismo (andar de bicicleta), o modo como é praticada a corrida, na comunidade, pode ser reflexo da ausência de locais que possibilitem sua expressão formal. Faltam pistas apropriadas; as condições das vias de trânsito, onde seriam desenvolvidas corridas de rua, são precárias; inexiste segurança pública. As questões de infraestrutura são reconhecidas como limitantes para a adesão ao comportamento ativo (SILVA, PETROSKI, REIS, 2009).

Outras comunidades quilombolas espalhadas pelo Brasil também demonstram práticas de outras atividades além do futebol e da caminhada. Em Invernada Paiol de Telha, Paraná, é recorrente a prática do caratê, por influência de agente externo, e de danças culturais afro-brasileiras (LARA et al., 2009). Em Saracura, Amazonas, foram encontradas as práticas de dança (com enfoque no resgate da matriz afro-brasileira), de natação e de vôlei, estas desenvolvidas informalmente (FREITAS; SILVA; GALVÃO, 2009).

Em Manoel Ciríaco dos Santos, comunidade paranaense, os adultos praticam dança, porém sem pretender o resgate cultural, e capoeira, que representa veículo de luta pela permanência na terra de residência (LARA, 2012). No Feixo, Paraná, a dança, sem conotação afro-brasileira, é comum entre os adultos mais jovens (LARA, 2012).

No quilombo de Murumurutuba, Amazonas, a natação (atividades aquáticas) e a dança, apesar da necessidade de colaboração de agentes externos, ainda apresentam características culturais quilombolas, sobretudo nos momentos tradicionais de comemoração (FREITAS, SILVA, GALVÃO, 2009). 
Ricardo Franklin de F. Mussi, Leila Maria P. T. Mussi, Atividades Físicas Praticadas no Tempo Livre... Cristiano de S. de Bahia e Angelo Maurício de Amorim

$\mathrm{Na}$ comunidade goiana de Kalunga, foi constatada a presença recorrente de atividades esportivas informais (natação, ciclismo), jogo de bilhar (contando com locais específicos), motociclismo, cavalgada e danças (como a Sussa, dança típica local, expressando o caráter cultural específico da comunidade) (SANTOS, 2010).

Como percebido em outras comunidades, Tomé Nunes apresenta manifestações culturais plenas de corporeidade. Há forte presença de danças culturais como o 'boi girá' e 'dança de roda' (TEIXEIRA, 2013b), no entanto, talvez por seu caráter hibrido com a religiosidade, elas não são reconhecidas como dança pelos quilombolas, não sendo citadas durante a pesquisa.

Outro aspecto evidenciado pelos resultados dessa pesquisa foi a forte ausência da prática das AFTL na comunidade $(52,7 \%)$, com predominância entre as mulheres e os mais velhos. Em uma investigação feita em Salvador, considerada capital de estado 'mais negra' do Brasil, a prevalência da inatividade física no tempo livre de adultos foi de 72\%, com predominância na faixa etária dos mais velhos (PITANGA; LESSA, 2005). Em outra pesquisa baiana feita apenas com pessoas negras, a prevalência da inatividade física foi de $88,8 \%$, estando especialmente associada às mulheres (PITANGA et al, 2012).

A inatividade física é a quarta causa de morte nos países em desenvolvimento (WHO, 2009). A prática regular de atividade física é importante contributo na prevenção e na terapia de doenças crônicas não-transmissíveis (hipertensão, diabetes, cardiopatias e outras) (AZEVEDO et al., 2008). Levando em consideração tais observações, se prevê que, em breve, estarão presentes, em Tomé Nunes, os principais problemas de saúde que atingem os grupos populacionais com comportamento sedentário. 
Ricardo Franklin de F. Mussi, Leila Maria P. T. Mussi, Atividades Físicas Praticadas no Tempo Livre... Cristiano de S. de Bahia e Angelo Maurício de Amorim

A significativa ausência de AFTL, em Tomé Nunes, pode estar relacionada com a opção por atividades sedentárias que requerem menor esforço físico e menor gasto energético, como o hábito de assistir televisão (ANJOS, 2001) ou às restritas oportunidades de praticar atividades físicas disponíveis na comunidade.

A comunidade baiana participante deste estudo não conta com nenhum profissional de Educação Física, ali não há política pública ou qualquer tipo de ação voltada para a orientação e o desenvolvimento de atividades físicas em suas diversas dimensões e representações, diferentemente, por exemplo, da realidade paranaense (LARA, 2012). Essa situação reverbera negativamente na diversificação de modalidades atléticas e em seu ajustamento à realidade e aos anseios da comunidade.

A presente investigação deparou-se com algumas limitações que não podem ser ignoradas. Seu caráter transversal constitui um desenho investigativo com restrito poder analítico. A utilização de questionário para coleta de dados é um instrumento reconhecidamente vulnerável à dificuldade compreensiva, à capacidade recordatória ou à omissão do participante. Como, no entanto, não são conhecidos instrumentos mais completos e específicos para os fins propostos, tal instrumento foi utilizado por ser validado (BRASIL, 2012) e ter ampla aceitação pela literatura.

Houve dificuldade para debater com a literatura, quer pelos perfis metodológicos das pesquisas que apresentam as AFTL em quilombolas, quer pelo perfil cultural das comunidades quilombolas e não quilombolas, o que dificultou o reconhecimento das manifestações das AFTL formais e não formais, esportivas ou esportivizadas.

Dentre os principais pontos positivos do presente estudo, está a obtenção de informações sobre uma comunidade rural, negra e quilombola, de uma região pobre do nordeste brasileiro. Regularmente, este tipo de comunidade é negligenciada pelo campo 
Ricardo Franklin de F. Mussi, Leila Maria P. T. Mussi, Atividades Físicas Praticadas no Tempo Livre... Cristiano de S. de Bahia e Angelo Maurício de Amorim

científico, pelas políticas públicas e pela sociedade, devido as dificuldades logísticas e de acesso. Ressalta-se o possível ineditismo das informações captadas, que poderão inclusive embasar propostas de intervenção em atividade física, em educação e em saúde adequadas ao perfil e à demanda da comunidade. Este pode ser um meio de ampliar a adesão às práticas corporais pelos quilombolas, especialmente pelos mais afetados por causa da ausência de AFTL em seu cotidiano (mulheres e mais velhos).

\section{CONSIDERAÇÕES FINAIS}

Na comunidade quilombola de Tomé Nunes, localizada no Alto Sertão baiano, dentre aqueles que declararam prática de atividade física no tempo livre, o futebol figura como representação esportiva predominante, independente de sexo e grupo etário. A caminhada, o ciclismo (andar de bicicleta), a corrida e a natação (atividades aquáticas) foram referidas como as principais atividades para ocupação do tempo livre.

Diferente de outras comunidades quilombolas, em Tomé Nunes, não há intervenções externas ou políticas públicas para orientação, incentivo ou acompanhamento de atividades físicas. Tal situação auxilia na explicação sobre a pouca quantidade de praticantes e a restrita variedade de modalidades.

Este estudo investigou a atividade física de tempo livre em comunidade negra, rural, quilombola e acabou demonstrando a força do fenômeno esportivo (futebol) contextualizado a suas demandas e realidades. Evidenciou igualmente um significativo número de adultos que parecem não realizar atividade física durante seu tempo livre.

É fundamental que, no tratamento das questões quilombolas, se aceite a imbricação da multiplicidade de elementos quanto ao reconhecimento de identidades, de direitos, de representação política, de redistribuição material e simbólica, que não 
Ricardo Franklin de F. Mussi, Leila Maria P. T. Mussi, Atividades Físicas Praticadas no Tempo Livre... Cristiano de S. de Bahia e Angelo Maurício de Amorim

devem ser confinados a categorias que estabeleçam separações estanques (MARQUES; GOMES, 2013).

Conclui-se que a prática de atividade física no tempo livre, com predominância dos esportes, é fruto da construção histórica, cultural e social, em consonância com o tempo e o desenvolvimento econômico e educacional, tendo abrangência identitária individual e coletiva e requerendo adaptações e adequações ao ambiente circundante.

\section{REFERÊNCIAS}

ABRAHÃO, B. O. L.; SOARES, A. J. G. Futebol e Lazer: uma análise sobre o "Racismo à Brasileira" através dos jogos "Preto X Branco". Licere, Belo Horizonte, v.15, n.3, p.1-24, 2012.

ACOSTA, M. A. F.; PACHECO, A. C. Lazer e Envelhecimento: olhares que entrelaçaram a cidade e o envelhecer. Licere, Belo Horizonte, v.16, n.3, p.1-19, 2013.

ALMEIDA, A. J. M.; ALMEIDA, D. M. F.; GRANDO, B. S. As Práticas Corporais e Educação do Corpo Indígena: a contribuição do esporte nos jogos dos povos indígenas. Revista Brasileira de Ciências do Esporte, Florianópolis, v.32, n.2-4, p.59-74, 2010.

ANJOS, L. A. Obesidade nas sociedades contemporâneas: o papel da dieta e da inatividade física. In: CONGRESSO BRASILEIRO DE ATIVIDADE FÍSICA E SAÚDE, 3, Florianópolis, 2001. Anais... Florianópolis: Universidade Federal de Santa Catarina, 2001.

AQUINO, C. A. B.; MARTINS, J. C. O. Ócio, lazer e tempo livre na sociedade do consumo e do trabalho. Revista Mal-estar e Subjetividade, Fortaleza, v.7, n.2, p.479$500,2007$.

ARCHETTI, E. Masculinidades: fútbol, tango y polo en la Argentina. Buenos Aires: Antropofagia, 2003.

AZEVEDO, M.R et al. Fatores associados ao sedentarismo no lazer de adultos na coorte de nascimentos de 1982, Pelotas. Revista de Saúde Pública, São Paulo, v. 42, n.2, p.70-77, dez. 2008.

BARBOSA, C.; LIECHTY, T.; PEDERCINI, R. Restrições ao Lazer Feminino. Licere, Belo Horizonte, v.16, n.2, p.1-22, 2013.

BASSET Jr., D. R. et al. Walking and measurement. Med. Sci. Sport Exerc. v.40, n.7, p. 529-536, 2008. 
Ricardo Franklin de F. Mussi, Leila Maria P. T. Mussi, Atividades Físicas Praticadas no Tempo Livre... Cristiano de S. de Bahia e Angelo Maurício de Amorim

BRASIL. Constituição da República Federativa do Brasil, 1988. Brasília: Senado Federal, Centro Gráfico, 1988.

BRASIL. Vigitel Brasil 2011: Vigilância de Fatores de Risco e Proteção para Doenças Crônicas por Inquérito Telefônico. Ministério da Saúde, Secretaria de Vigilância em Saúde. Brasília: Ministério da Saúde, 2012.

CARVALHO, M. L.; FREITAS, C. M. Pedalando em busca de alternativas saudáveis e sustentáveis. Ciência \& Saúde Coletiva, v.17, n.6, p.1617-1628, 2012.

CASPERSEN, C. J.; MERRIT, R. K.; STEPHENS, T. International physical activity patterns: a methodological perspective. In: DISHMAN, R. K. (Org.). Advances in exercise adherence. Champaign: Human Kinetics, 1995. p.73-110.

DAÓLIO, J. As Contradições do Futebol Brasileiro. In: CARRANO, P. C. R. (Org.). Futebol: paixão e política. Rio de Janeiro: DP\&A Editora, 2000, v. 01, p. 29-44.

DEBORTOLI,, J. A. O. Lazer, Envelhecimento e Participação Social. Licere, Belo Horizonte, v.15, n.1, p.1-29, 2012.

DIAS, C. Esporte e Lazer em Culturas Tradicionais. In: SILVA, A. M.; FALCÃO, J. L. C. (Org.) Práticas corporais em comunidades quilombolas de Goiás. Goiânia: PUC Goiás, 2011. p.93-115.

DIAS, C. A. sociologia figuracional e os estudos do esporte. Revista Brasileira de Ciências do Esporte, Campinas, v. 31, n. 2, p.155-169, 2010.

DIAS, D. C.; FONSECA, Z. V. D. Esporte e Lazer como Necessidade Humana: Inflexões. In: Diagnóstico do Esporte e Lazer na Região Norte Brasileira: o existente e o necessário. SOARES, A. et al. (Org.) Manaus: Educa, 2011. p.14-27.

FERREIRA, R. J.; KLEINUBING, M. C. Natação: relações do corpo com a água [...] Em busca do prazer. Arquivos de Ciências da Saúde da UNIPAR, Umuarama, v.7, n.2, p.159-66, 2003.

FREITAS, D. B.; SILVA, J. M.; GALVÃO, E. F. C. A relação do lazer com a saúde em comunidades quilombolas de Santarém. Revista Brasileira de Ciências do Esporte, Campinas, v.30, n.2, p.89-105, 2009.

GOELLNER, S. V. Mulher e Esporte no Brasil: entre incentivos e interdições elas fazem história. Pensar a Prática, Goiânia, v.8, n.1, p.85-100, 2005.

GOELLNER. S. V. et al. Gênero e Raça: inclusão no esporte e lazer. Porto Alegre: Ministério do Esporte/Gráfica da UFRGS, 2009.

Lazer e gênero nos programas de esporte e lazer das cidades. Licere, Belo Horizonte, v.13, n.2,p.1-20, 2010. 
Ricardo Franklin de F. Mussi, Leila Maria P. T. Mussi, Atividades Físicas Praticadas no Tempo Livre... Cristiano de S. de Bahia e Angelo Maurício de Amorim

HASENBALG, C. A.; SILVA, N. V. Notes on racial and political inequality in Brazil. In: HANCHARD, M. (ed.). Racial politics in contemporary Brazil. Durham/London: Duke University Press, 1999. p. 154-78.

HOLLANDA, B. B. B. O futebol como alegoria antropofágica: modernismo, música popular e a descoberta da "brasilidade" esportiva. Artelogie (Online), v.1, p.1-12, 2011.

IBGE. Instituto Brasileiro de Geografia e Estatística. Censo Demográfico 2000. Características da População e dos Domicílios. Resultado do universo. Rio de Janeiro: FIBGE, 2002.

IBGE. Instituto Brasileiro de Geografia e Estatística. IBGE cidades. Disponível em: http://www.cidades.ibge.gov.br/xtras/perfil.php?lang=\&codmun=292020\&search=bahia malhada . Acesso em: 29 Jun, 2014.

LARA, L. M. Esporte e Lazer em Comunidades Quilombolas no Paraná: identificando realidades e apontando desafios para implementação e/ou aprimoramento de Políticas Públicas. Pensar a Prática, Goiânia, v.15, n.1, p.37-51, 2012.

LARA, L. M. et al. Esporte e lazer na comunidade quilombola Invernada Paiol da Telha: realidade, perspectivas e desafios. In: CONGRESSO INTERNACIONAL DE CIÊNCIAS DO ESPORTE, 3, 2009, Salvador, Anais... Salvador: CBCE, 2009, s/p.

MALAIA, J. M. O processo de profissionalização do futebol no Rio de Janeiro: dos subúrbios à Zona Sul. A inserção de negros, mestiços e brancos pobres na economia da Capital Federal (1914-1923). Leituras de Economia Política, Campinas, v. 13, p.125$155,2008$.

MARQUES, A. T.; GAYA, A. Atividade física, aptidão física e educação para a saúde: estudos na área pedagógica em Portugal e no Brasil. Revista Paulista de Educação Física, São Paulo, v.13, n.1, p.83-110, 1999.

MARQUES, C. E.; GOMES, L. A constituição de 1988 e a ressignificação dos quilombos contemporâneos: limites e potencialidades. Revista Brasileira de Ciências Sociais, São Paulo, v.28, n.81, p. 137-153, 2013.

MAZO, G. Z.; LOPES, M. A.; BENEDETTI, T. B. Atividade Física e o Idoso: Concepção Gerontológica. 3. ed. rev. e ampl. Porto Alegre: Sulina, 2009. 318 p.

MOURA, D. L. et al. ESPORTE, MULHERES E MASCULINIDADES. Esporte e Sociedade, Niterói, v.5, n.13, p.1-22, 2010.

NAHAS, M. V. Atividade Física, Saúde e Qualidade de Vida: conceitos e sugestões para um estilo de vida ativo. 6 ed. rev. e atual. Londrina: Midiograf, 2013.

PETROSKI, E. L.; OLIVEIRA, M. M. Atividade física de lazer e estágios de mudança de comportamento em professores universitários. Revista Portuguesa de Ciência do Desporto, Porto, v.8, n.2, p.209-218, 2008 
Ricardo Franklin de F. Mussi, Leila Maria P. T. Mussi, Atividades Físicas Praticadas no Tempo Livre... Cristiano de S. de Bahia e Angelo Maurício de Amorim

PITANGA, F. J. G. et al. Fatores sociodemográficos associados aos diferentes domínios da atividade física em adultos de etnia negra. Revista Brasileira de Epidemiologia, São Paulo, v.15, n.2, p.363-75, 2012.

PITANGA, F.J.G.; LESSA, I. Prevalência e fatores associados ao sedentarismo no lazer em adultos. Cadernos de Saúde Pública, Rio de Janeiro, v. 21, n.3, p. 870-77, 2005.

ROLDAN, T. R. R. Cicloturismo: planejamento e treinamento. 2000. 74f. Monografia (Bacharelado em Treinamento em Esportes), Universidade Estadual de Campinas, Campinas/SP, 2000.

SANTOS, M. P. O. As Práticas Corporais na Comunidade Kalunga - GO. In: CONGRESSO CENTRO-OESTE DE CIÊNCIAS DO ESPORTE, 4, 2010, Brasília. Anais... Brasília: CBCE, 2010. s/p

SILVA, L. R. F. Da velhice à terceira idade: o percurso histórico das identidades atreladas ao processo de envelhecimento. História, Ciências, Saúde - Manguinhos, Rio de Janeiro, v.15, n.1, p.155-168, 2008.

SILVA, D. A. S.; PETROSKI, E. L.; REIS, R. S. Barreiras e facilitadores de atividades físicas em frequentadores de parques públicos. Motriz, Rio Claro, v.15, n.2, p.219-27, 2009.

SIQUEIRA, M. E. C. Teorias Sociológicas do Envelhecimento. In: FREITAS, E. V. et. al. (Org.) Tratado de Geriatria e Gerontologia. Rio de Janeiro: Editora Guanabara Koogan, 2002.

SODRÉ, M. A verdade seduzida - Por um conceito de cultura no Brasil. 3 ed. Rio de Janeiro: DP \& A, 2005.

STIGGER, P. M. Educação Física, Esporte e Diversidade. Campinas: Autores Associados, 2005.

TEIXEIRA, L. M. P. Comunidade de Tomé Nunes: memória e construção identitária no Alto Sertão baiano. 2010. 122 f. Dissertação (Mestrado em História Regional e Local), Universidade do Estado da Bahia, Santo Antônio de Jesus/BA, 2010.

Cultura, tradição e identidade em comunidade ribeirinha do São Francisco. In: Encontro Estadual de História, 6, 2013, Ilhéus. Anais... Ilhéus: ANPUH/BA, 2013b. s/p.

"Essa terra nos pertence, essa terra é terra dos antepassados": A luta pela terra na comunidade negra de Tomé Nunes - Malhada/BA. In: Simpósio Nacional de História - ANPUH, 26, 2011, São Paulo. Anais... São Paulo: ANPUH, 2011. s/p.

. Negras Guerreiras: O papel feminino e suas conquistas para Comunidades Tradicionais. In: COLÓQUIO INTERNACIONAL DO MUSEU PEDAGÓGICO, 3, 2013, Vitória da Conquista. Anais... Vitória da Conquista: UESB, 2013. s/p. 
Ricardo Franklin de F. Mussi, Leila Maria P. T. Mussi, Atividades Físicas Praticadas no Tempo Livre... Cristiano de S. de Bahia e Angelo Maurício de Amorim

WARBURTON, D. E. R.; NICOL, C. N.; BREDIN, S. S. D. Health benefits of physical activity, the evidence. Canadian Medical Association Journal, v.174, n. 6, p. 801$809,2006$.

WEINBERG, R. S.; GOULD, D. Fundamentos da Psicologia do Esporte e do Exercício. 4 ed. Porto Alegre: Artmed Editora, 2008.

WHO, WORLD HEALTH ORGANIZATION. Global health risks. Mortality and burden of disease attributable to selected major risks. 2009. Disponível em $<$ http://www.who.int/healthinfo/global_burden_disease/GlobalHealthRisks_report_full. pdf $>$ Acesso em 21.mar.2014.

\section{Endereço dos Autores:}

Ricardo Franklin de Freitas Mussi

Universidade do Estado da Bahia

Departamento de Ciências Humanas

Campus IV

CEP: 44.700-000 - Jacobina - BA

Endereço Eletrônico: rimussi@yahoo.com.br 